\title{
Das bibliotecas convencionais às digitais: diferenças e convergências
}

\section{Murilo Bastos da Cunha}

\author{
Universidade de Brasília - Departamento \\ de Ciência da Informação e Documentação
}

Comentam-se as diferenças e convergências entre a biblioteca convencional e a digital, apontando quatro aspectos, a saber: 1) a organização da informação, mostrando que a biblioteca digital tem um potencial informacional que dificilmente terá sido alcançado pela biblioteca convencional: ela pode entregar a informação diretamente na mesa do usuário. Discute o futuro do catálogo da biblioteca em relação aos mecanismos de busca e aos projetos de digitalização em massa; 2) o acesso à informação, mostrando que este é o momento de se iniciar uma integração das fontes e materiais eletrônicos nos acervos e serviços; 3) o aspecto econômico, mostrando que muitas bibliotecas procuram no ambiente externo aquelas fontes de informação que poderão ser úteis, digitalizam seus conteúdos e os colocam à disposição de sua comunidade; 4) as ações cooperativas, afirmando que houve um incremento das atividades de cooperação bibliotecária, não somente para reduzir os custos, mas também para facilitar a sobrevivência da biblioteca como instituição social. Conclui-se que o desafio da mudança é uma oportunidade de renovação para a biblioteca, fazendo com que ela continue a ser um espaço de prazer e aprendizado.

Palavras-chave: Acesso à informação, Biblioteca digital, bibliotecário, Cooperação bibliotecária, Digitalização, Google, Internet.

\section{From conventional to digital libraries: differences and convergences}

The differences and convergences between traditional and digital libraries are discussed. Four aspects are analyzed in this paper, i.e.: 1) the organization of the information where it is shown that the digital library has an information power that will hardly be reached by the conventional library, as information can be directly 
delivered to the user's desk; the future of the library catalog is also discussed and compared to search engines and mass digitalization projects; 2) the access to information, pointing the present as the right time to start the integration of sources and electronic materials into library collection and services; 3) economical aspects showing that many libraries try to obtain helpful information sources in the external environment, and digitalize their contents to make them available to its clientele; 4) cooperative actions, observing that library cooperation activities increased, not only to reduce costs but also to facilitate survival of the library as a social institution. Finally, the article points out that the challenge to change is a great opportunity for revitalization of the library, impelling it to continue to be a space for joy and learning.

Keywords: Access to information, Digital library, Digitalization, Google, Internet, Librarian, Library cooperation.

Recebido em 11.01.2008 Aceito em 06.03.2008

\section{A idéia da biblioteca universal não é tão nova assim...}

Ao se falar de uma biblioteca que tenta reunir o máximo de documentos publicados em todos os países, ou que disponibiliza o seu acervo para pessoas residentes nos mais diversos rincões de um país ou de continentes, a primeira impressão que se tem é de se estar falando de algo muito novo. Na verdade, esta idéia é bem antiga.

Em 1895, dois advogados belgas, Paul Otlet e Henri La Fontaine, criaram, em Bruxelas, o Instituto Internacional de Bibliografia, "cujo objetivo era registrar em fichas a produção mundial de impressos: o Repertório Bibliográfico Universal, então inaugurado naquela cidade" (FONSECA, 2007, p. 4). Ressalte-se que o Brasil, por iniciativa de Manuel Cícero Peregrino da Silva, então diretor da Biblioteca Nacional, do Rio de Janeiro, colaborou com esse pioneiro Repertório, enviando os dados sobre a produção bibliográfica brasileira (FONSECA, 2007).

Pouco se menciona na nossa literatura biblioteconômica que a dupla Otlet e La Fontaine projetaram em 1908 - um século atrás - uma biblioteca central internacional, que fracassou por causa das dificuldades de manutenção de uma colaboração homogênea entre os diversos países e por problemas técnicos que surgiram no momento de processar a informação em países de culturas heterogêneas (LÓPEZ YEPES, 2002). Como se depreende, a noção da importância da padronização nas atividades de processamento técnico levou muito tempo para ser entendida pela maioria dos bibliotecários. 
Em 1938, H. G. Wells sugeriu a criação de uma enciclopédia universal, que conteria a memória planetária completa para toda a humanidade. Em 1945, Vannevar Bush - assessor científico do governo norte-americano - descreveu uma visão própria, em que imaginava:

um futuro dispositivo para uso individual que seja uma espécie de arquivo e biblioteca privada mecanizada. Precisa-se de um nome, e escolhemos um ao acaso, MEMEX. Um MEMEX é um dispositivo em que um indivíduo armazena todos os seus livros, dados e mensagens, estando mecanizado de tal maneira que possa ser consultado com grande velocidade e flexibilidade. (...) parece uma mesa de escritório. Numa extremidade está o material armazenado. A grande massa do material se guarda em microfilme. Somente uma pequena parte do interior do MEMEX está dedicada à memória, o resto é o mecanismo. Se o usuário introduzisse 5.000 páginas de material por dia, levaria centenas de anos para completar o depósito, de modo que se pode introduzir material à vontade. (...) Se o usuário deseja consultar um determinado livro, digita o código no teclado e o título do livro aparece em seguida, projetado sobre uma das telas. (...) Desta forma, pode-se solicitar qualquer livro de sua biblioteca e consultá-lo de forma mais fácil do que se tivesse que retirá-lo de uma estante. (...) Aparecerão formas completamente novas de enciclopédias, feitas com uma trama de cadeias associativas, prontas para serem introduzidas no MEMEX e ali ampliadas. (BUSH, 1945, p 102-104)

Como se pode notar, Bush previu um sistema parecido com o hipertexto, e o MEMEX - que seria um computador provido com um banco de dados, contendo a literatura técnico-científica necessária ao exercício profissional do pesquisador moderno - permitiria estabelecer comunicação com os pares, hoje realizada por meio da internet.

\section{Diferenças entre a biblioteca convencional e a digital}

A seguir, serão comentadas as diferenças básicas entre a biblioteca convencional e a digital. Também serão analisados os aspectos onde haverá convergências, pois, apesar das dificuldades financeiras que geralmente a biblioteca convencional enfrenta, as novas tecnologias foram, paulatinamente, incorporadas às suas atividades, provocando mudanças internas e na maneira de prover produtos e serviços informacionais aos usuários.

\subsection{A organização da informação}

A biblioteca convencional é aquela em que a maioria dos itens do seu acervo é constituída de documentos em papel. Ela existe desde a 
invenção da escrita. É claro que, antes do advento da imprensa de tipos móveis, em 1440, o seu acervo era formado por outros tipos de materiais (como o tablete de argila, o papiro e o pergaminho). Uma característica da biblioteca convencional é que tanto a coleção como os seus catálogos utilizam o papel como suporte de registro da informação. Todavia, no final do século XIX, houve uma grande revolução na biblioteca, com a introdução do catálogo em fichas e o abandono do catálogo sob a forma de livro. Nas últimas décadas, o computador tem sido utilizado de forma cada vez mais crescente $e$, desde os anos 1970, muitas bibliotecas implantaram catálogos em linha, passaram a acessar bancos de dados, iniciaram o uso regular do periódico eletrônico e o acesso a textos completos de artigos de periódicos, a verbetes de enciclopédias e a itens de outras fontes de referência. A partir de 1994, por exemplo, com a implantação da World Wide Web (WWW) e do fenomenal crescimento da Internet, as possibilidades de acessar e recuperar informações aumentaram de forma nunca antes imaginada (CUNHA, 1999).

A biblioteca digital combina a estrutura e a coleta da informação, tradicionalmente usada por bibliotecas e arquivos, com o uso da representação digital tornada possível pela informática. A informação digital pode ser rapidamente acessada em todo o mundo, copiada para preservação, armazenada e recuperada rapidamente. À semelhança da biblioteca convencional, a biblioteca digital também inclui os princípios consagrados de como a informação é organizada. Ressalta-se que não seriam verdadeiras bibliotecas digitais aquelas coleções eletrônicas selecionadas e disponibilizadas por indivíduos na Web. Uma biblioteca digital - uma coleção de informação digitalizada e organizada - tem um potencial informacional que dificilmente terá sido alcançado por alguma biblioteca convencional, isto é, ela pode entregar a informação diretamente na mesa do usuário (à semelhança da máquina Memex, imaginada por Vannevar Bush), possui a capacidade de executar estratégias de busca por palavras isoladas ou por expressões inteiras, e o seu conteúdo informacional - seja ele na forma textual, sonora ou em imagens - não sofre os desgastes naturais decorrentes do uso intensivo do documento impresso.

Biblioteca digital é um conceito emergente. Mas, o que é necessário para construir uma biblioteca digital? Primeiramente, ela precisa ter conteúdo, que pode ser material antigo, convertido no formato digital, ou material novo, nascido digitalmente. Os itens que formam o seu acervo podem ser comprados, doados, trocados ou digitalizados localmente, a partir de documentos que não mais estão sujeitos aos ditames legais do direito autoral. Parecida com a convencional, a biblioteca digital apresenta:

um modelo transformativo em larga escala, uma organização centrada no usuário, movendo-se de forma integrada entre os seus componentes. Entretanto, o objetivo maior da biblioteca digital é consistente com aquele da biblioteca convencional, 
isto é, organizar, distribuir e preservar os recursos informacionais (CHOI; RASMUSSEN, 2006, p. 01).

A prioridade de alinhar as aplicações da biblioteca digital com a coleção e os serviços da biblioteca convencional está exigindo que as habilidades profissionais do quadro de pessoal atendam a essas novas dimensões da prática bibliotecária (CHOI; RASMUSSEN, 2006). Essas qualificações estão mencionadas no Quadro 1 (QUAD. 1), segundo levantamento realizado por Choi e Rasmussen, em 2006, junto a profissionais norte-americanos, utilizando a escala de Likert de cinco pontos. Infelizmente, ainda não existem, no contexto educacional brasileiro, cursos regulares que possam preparar o profissional para gerenciar, da melhor forma possível, um projeto de biblioteca digital. Os atuais gerentes deste tipo de projeto estão aprendendo com a prática! 0 mesmo fenômeno também ocorre na maioria dos outros países comprovando que a biblioteca digital ainda está em fase de amadurecimento nos cursos de ciência da informação.

QUADRO 1 -Habilidades profissionais necessárias em bibliotecas digitais

\begin{tabular}{l|l|l}
\hline \multicolumn{1}{c|}{ Tecnologia } & \multicolumn{1}{|c}{ Biblioteconomia } & \multicolumn{1}{c}{ Outros } \\
\hline $\begin{array}{l}\text { Arquitetura e software de } \\
\text { biblioteca digital }(4,52)\end{array}$ & $\begin{array}{l}\text { Necessidades dos usuários } \\
(4,52)\end{array}$ & $\begin{array}{l}\text { Comunicação interpessoal } \\
(4,60)\end{array}$ \\
\hline $\begin{array}{l}\text { Normas e padrões de } \\
\text { qualidade }(4,33)\end{array}$ & Preservação digital $(4,42)$ & $\begin{array}{l}\text { Gerenciamento de projetos } \\
(4,56)\end{array}$ \\
\hline $\begin{array}{l}\text { Linguagens de marcação } \\
(4,04)\end{array}$ & $\begin{array}{l}\text { Catalogação, metadados } \\
(4,0)\end{array}$ & Problemas legais $(3,90)$ \\
\hline $\begin{array}{l}\text { Sistemas de gerenciamento } \\
\text { de base de dados }(3,77)\end{array}$ & Indexação $(3,71)$ & $\begin{array}{l}\text { Captação de recursos }(3,88) \\
\text { Web design (3,71) }\end{array}$ \\
\hline
\end{tabular}

FONTE - CHOI E RASMUSSEN (2006).NOTA- entre parêntesis está a média na escala de Likert de cinco pontos.

Neste momento, de acordo com o Quadro 2 (QUAD. 2) surge outra diferença entre a biblioteca convencional e a digital. Na biblioteca digital, os "documentos" são compostos por uma variedade de tipos e componentes multimídia, que agregam um número ilimitado de formatos. Estes, por exemplo, podem misturar textos, tabelas e dados científicos obtidos de dados observados, ou podem integrar imagens em três dimensões, anotações e vídeos (CASTELLI, 2006, p. 497).

\section{QUADRO 2- Exemplos de documentos do acervo}

\begin{tabular}{|c|c|}
\hline $1 \quad$ Biblioteca convencional & Biblioteca digital \\
\hline $\begin{array}{ll}\cdot & \text { Livros } \\
- & \text { Índices/bibliografias } \\
- & \text { Obras de referência } \\
\text { - } & \text { Periódicos }\end{array}$ & $\begin{array}{ll}- & \text { Os mencionados na biblioteca } \\
& \text { convencional mais: } \\
\text { - } & \text { Dados numéricos } \\
\text { - } & \text { Imagens } \\
\text { - } & \text { Som } \\
\text { - } & \text { Textos codificados } \\
\text { - } & \text { Dados especiais }\end{array}$ \\
\hline
\end{tabular}

FONTE - CUNHA (1999 e 2000). 
A catalogação original, tanto para itens impressos quanto para os digitais, não desaparecerá. Entretanto, esta tarefa provavelmente ficará restrita a grandes bibliotecas ou àquelas muito especializadas, ou a serviços bibliográficos em linha (bibliographic utility). Será comum o downloading do registro catalográfico para o catálogo local, o qual terá ligações (links) para as bibliotecas hospedeiras dos documentos digitais (CUNHA, 2000).

O armazenamento digital amplia as possibilidades de pontos de acesso a um determinado documento. Nos sistemas manuais tradicionais, e mesmo nos catálogos automatizados produzidos até o final dos anos 1980, as descrições mínimas restringiam-se a dados sobre o autor, título e alguns cabeçalhos de assunto. Atualmente, dezenas de termos de indexação podem ser incluídos e, também, diversos níveis de representação do documento. Tais características agregam, sobremaneira, um alto grau de flexibilidade e qualidade na busca e recuperação da informação. Além disso, no caso de periódicos eletrônicos, por exemplo, as várias partes do documento, como objeto físico, podem ficar hospedadas em diversos computadores.

O paradigma da unidade representativa da informação era, por exemplo, um livro, e não os seus capítulos. Entretanto, em uma coleção digital heterogênea, os níveis de representação do conteúdo alcançam detalhes inimagináveis, podendo ser um mapa, uma figura, um filme, um slide, um capítulo ou mesmo um verbete de uma obra de referência. A política de indexação seguida pela biblioteca é que irá delinear quais níveis de representação da informação serão adotados em um determinado acervo. Obviamente, essas decisões terão muitas implicações na representação do conteúdo a ser utilizado, com reflexos no tamanho do arquivo invertido e nos mecanismos de busca. Espera-se, por exemplo, que os atuais sistemas de automação das bibliotecas convencionais possam usufruir dos avanços que já estão ocorrendo nas bibliotecas digitais.

Em relação ao catálogo da biblioteca (o automatizado e o automatizado de acesso público em linha, o OPAC), vale a pena discutir o seu futuro em face dos mecanismos de busca e dos projetos de digitalização em massa. Deana Marcum, diretora dos Serviços Bibliotecários da Library of Congress, sugeriu que:

a atenção detalhada que temos tido com a catalogação descritiva pode não ser mais justificada (...) catalogadores devem gastar mais tempo com o controle dos termos autorizados [authority control], análise de assuntos, identificação e avaliação do recurso informacional (MARCUM, 2006, p. 08).

Alguns autores estão propondo mudanças mais radicais, Karen Markey observou que:

por uma década e meia, começando no início dos anos 1980, o catálogo em linha da biblioteca era a jóia da coroa, quando as 
pessoas ávidas aguardavam nas filas dos terminais para procurarem informações escritas por especialistas mundiais. Fico abismada em relação ao modo como as pessoas ávidas agora abraçam o Google, devido à fonte de informação que o Google recupera. Anos atrás, poderíamos ter adicionado maior valor ao catálogo em linha da biblioteca, mas a única coisa que mudamos foi o formato do catálogo. (...) [esse período] foi a idade de ouro do catálogo em linha, porque os usuários da biblioteca dependiam exclusivamente dele para encontrar um tópico que lhes interessava (MARKEY, 2007, p. 02).

É um mito pensar que o usuário sempre planeja a estratégia de busca ou que faz buscas muito elaboradas ou avançadas. Uma busca geralmente corrobora o princípio do menor esforço; o usuário deseja que o sistema recupere informação com qualidade e que ele tenha facilidade na utilização. Esse comportamento do usuário se aplica tanto à biblioteca convencional quanto à digital.

\subsection{0 acesso à informação}

Na fase pioneira, até os anos 1980, as aplicações do computador na biblioteca convencional quase sempre tiveram seus impactos concentrados nos processos técnicos. Os bibliotecários receberam de bom grado a tecnologia, que possibilitou fazer as coisas de uma maneira mais fácil e rápida. Nos últimos tempos, a partir da década de 1990, com o crescente domínio da tecnologia de informação, esses profissionais iniciaram um refinamento dos procedimentos automatizados. Agora, com a biblioteca digital, a atual revolução tecnológica apresenta novas oportunidades de mudança. Este é o momento de avançar para além dos aspectos relativos à aquisição e ao processamento dos materiais, integrando fontes e materiais eletrônicos nos acervos e serviços. É tempo de parar de pensar somente em termos de fontes impressas e disponibilidade dos documentos, mesmo que essas fontes ainda predominem em nossas coleções (CUNHA, 1999).

Como já se mencionou, a biblioteca digital pode conter diferentes tipos de suportes informacionais (mídias informacionais) sobre os mais variados assuntos. Já na biblioteca convencional, é comum a organização desses suportes informacionais variados em setores específicos distribuídos no organograma da instituição. Assim, por exemplo, encontram-se ali o setor de periódicos, a mapoteca e o setor de multimeios, organizando-se a biblioteca por meio da separação dos documentos pelo seu tipo de suporte informacional. Na biblioteca digital, entretanto, todo o conteúdo informacional está num único formato equivalente - o digital.

A ênfase do foco da biblioteca digital é maior no acesso e menor na coleção. Considerando que o material pode estar disponível num sítio em linha, os bibliotecários dessa biblioteca podem utilizar mais os seus conhecimentos técnicos na obtenção de documentos fora da localização 
física, bem como conhecer também o estoque informacional armazenado no prédio ou sob o seu controle. Assim, a organização da biblioteca digital deve refletir-se nos documentos que os usuários desejam, e não naqueles que o bibliotecário tem condições para incorporar ao acervo. Ela também dará suporte na busca e na aquisição da informação; deverá também ter um maior envolvimento com as necessidades dos usuários.

Aqui não pode ser negligenciado o papel da Internet junto aos cidadãos. Em muitos casos, a Web será a fonte provedora da maior parte da informação daquelas pessoas que têm acesso à Internet. Considerando o irrefreável crescimento da internet, não é mais necessário questionar a qualidade da informação nela armazenada - ela está aí disponível, vinte e quatro horas por dia, durante os sete dias da semana! O que precisa ser indagado aqui é o que a biblioteca, seja ela convencional ou digital, poderia fazer para ajudar e aconselhar aqueles que têm dificuldades de avaliar o conteúdo e a utilidade das informações hospedadas nessa rede.

Existe uma necessidade crítica de aumentar a percepção da população brasileira em relação às bibliotecas. As habilidades dos bibliotecários em interpretar a tecnologia precisam ser conhecidas. Infelizmente, parece que essas habilidades ficam restritas ao 'gueto profissional' dos periódicos e eventos da nossa área. Apesar de tudo, a imagem pública das bibliotecas continua vinculada ao livro, e quando as pessoas refletem sobre o papel das bibliotecas em relação ao aspecto tecnológico, muitas delas imaginam que o livro impresso vai desaparecer e, por conseqüência, a biblioteca também. Essa idéia faz com que aumentem as dificuldades para a obtenção de fundos financeiros para a biblioteca, com o que se rejubilam os administradores públicos, pois, desta forma, não se sentem no dever de destacar verbas para as bibliotecas convencionais. Neste contexto, a grande massa dos leitores potenciais poderá se beneficiar dessas habilidades especiais dos bibliotecários, solicitando a assistência destes na busca de informações na Internet, no processo de escolha das homepages mais relevantes e na tarefa de fazer conexões entre os recursos informacionais dispersos em várias mídias. Aqui vale a pena ressaltar que a divulgação destas habilidades técnicas poderá fazer com que os cidadãos entendam que a biblioteca abriga todas as mídias informacionais.

Agora os setores de referência e desenvolvimento de coleções deverão estar intimamente interligados, pois a biblioteca digital irá forçar todas as bibliotecas a resolverem as necessidades dos seus usuários de forma prioritária e imediata (CUNHA, 1999). Além disto, tendo em vista as imensas possibilidades advindas de, por meio de contratos, ser possível acessar repositórios de informação hospedados em computadores diversos, haverá uma redução das diferenças entre as pequenas e grandes bibliotecas, como também entre os diversos tipos de bibliotecas. O tamanho do acervo terá menos importância (DEMAS, 1994), pois o que irá contar daqui para frente serão as opções para acessar a informação demandada; e o diferencial para caracterizar uma biblioteca estará na verba disponível para resolver os problemas de acesso - uma pequena 
biblioteca tendo um orçamento adequado poderá ter o mesmo potencial informacional que uma biblioteca de grande porte de trinta anos atrás.

Esta mudança do paradigma de posse do documento para o de provisão de acesso já está causando efeitos na biblioteca convencional. Assim, a métrica de avaliar a qualidade da biblioteca pela quantidade de usuários que utilizam as suas mesas e salas de leitura precisa ser repensada. À medida que esta biblioteca vai ampliando os recursos tecnológicos - facilitando o acesso ao seu catálogo via Internet, via OPAC (catálogo público de acesso em linha), aumentando o acesso ao texto completo de periódicos eletrônicos, via Portal da Capes, por exemplo haverá menos necessidade de o usuário se deslocar fisicamente até o prédio da biblioteca. Nos tempos atuais é crescente o percentual de pessoas que estão lendo mais e copiando documentos em seus computadores pessoais. Tais fatos farão com que a biblioteca não tenha tanta necessidade de expandir a sua área física nem prover mais mesas e cadeiras para leitura; também farão com que economize seus recursos com gastos com o espaço físico e com a expansão do quadro de pessoal; assim, ela concentrará recursos na modernização do seu parque tecnológico.

A facilidade com que a biblioteca digital pode fazer trafegar um documento de um local para o outro leva a concluir que as ações cooperativas com entidades congêneres venham a ser estimuladas. O seu usuário não fica sabendo se o computador, que hospeda o acervo que ele está consultando para pedir cópia de um documento, está localizado no outro lado da rua ou a milhares de quilômetros. Por exemplo, para um professor universitário que esteja utilizando o Portal da Capes, não importa se o artigo do qual ele precisa fazer um download esteja armazenado num computador localizado nos Estados Unidos ou em algum país europeu! Para essa pessoa, o que importa é que o texto completo do documento seja conseguido de forma rápida, econômica e sem dificuldades de outra natureza.

\subsection{0 aspecto econômico}

Determinados itens demandados pelos usuários estarão armazenados em outras bibliotecas digitais e nem sempre estarão disponíveis sem custo. As bibliotecas digitais irão requerer dos usuários pagamentos para os detentores dos direitos autorais numa maneira jamais imaginada no mundo não digital. Os direitos autorais e o gerenciamento dos direitos autorais estarão interligados para possibilitar o acesso autorizado às informações sob diferentes formas, criadas sob diversos sistemas de propriedade intelectual, quer seja um impresso, um filme, uma mídia sonora ou uma fotografia.

Para uma grande parcela de usuários pode parecer que tudo o que está disponível na Internet é gratuito. Isto pode ser uma meia-verdade. Por exemplo, se o Projeto Gutenberg disponibiliza o acesso gratuito, a milhares de leitores, de 20000 livros com texto integral, isto nos faz 
lembrar que estes títulos estão acessíveis porque já estão sob o domínio público, isto é, não mais detém os direitos autorais.

Sherman aponta que:

os livros são justamente a ponta do iceberg. Numerosos artigos acadêmicos, periódicos e outros documentos importantes estão virtualmente inacessíveis para alguém que esteja desejando copiá-los de forma gratuita. Ao contrário, o acesso é restrito por meio de assinaturas caras, as quais são tipicamente pagas por bibliotecas. Visitar pessoalmente a biblioteca ou conectar-se a ela é o único caminho permitido para acessar os necessários recursos arquivados (SHERMAN, 2007, p. 67).

$\mathrm{Na}$ implantação de coleções digitais, muitas bibliotecas procuram no ambiente externo aquelas fontes de informação que poderão ser úteis para seus usuários. Outras selecionam documentos isentos de direitos autorais, digitalizam seus conteúdos e os colocam à disposição de sua comunidade. Isto tem sido feito principalmente com obras raras e manuscritos, e, após a existência do documento digital, que amplia a sua disponibilidade, a preservação do original poderá ser feita a custos menores.

Nem tudo está disponível na Internet; o impressionante volume de informação ali armazenado pode causar a falsa impressão de que tudo está disponível em linha. Daí a importância crescente da digitalização do acervo que envolve custos referentes a recursos humanos, equipamentos, indexação (manual e/ou automática) e controle de qualidade. Nesta área, um fato recente vem alterando o contexto bibliotecário mundial, causando polêmica em muitos países. É o Google Book Search, programa de digitalização em massa, lançado pelo Google em 14 de dezembro de 2004, que "pretende digitalizar 15 milhões de livros de cinco grandes bibliotecas universitárias dos Estados Unidos e Reino Unido" (BEARMAN, 2006, p. 01). Este programa recebeu enormes críticas, notadamente da França, por meio do diretor da sua Biblioteca Nacional. Estas reações estimularam a mobilização das bibliotecas nacionais européias no sentido de ampliar seus programas de digitalização, o que culminou com 0 lançamento da European Digital Library. Os cinco tópicos relevantes desta reação podem ser descritos conforme os itens a seguir:

1) "o Google não terá condições de digitalizar tudo o que foi impresso e a sua seleção irá favorecer as fontes americanas ou na língua inglesa em detrimento de outras culturas" (BEARMAN, 2006, p. 02). Essa seleção parcial poderá favorecer os países ricos em detrimento dos pobres que, por possuírem culturas vulneráveis, serão deixadas de fora do mundo digital para sempre ou por um longo período.

2) "a apresentação dos textos baseada em palavras os descontextualiza causando prejuízos culturais, e o interesse 
primário dela é a colheita de palavras para "lincar" anúncios" (BEARMAN, 2006, p. 02);

3) "o mecanismo de busca do Google (e o seu plano de negócios) promove resultados que não são consistentes com as classificações que os eruditos ligados às culturas nas quais os textos foram escritos iriam aprovar" (BEARMAN, 2006, p. 02);

4) "permitir que uma empresa privada tenha a posse de uma biblioteca digital de imagens ou textos em OCR [optical character recognition, reconhecimento ótico de caracteres] não parece ser um plano de preservação para as bibliotecas ou culturas mundiais, desencorajando os esforços para a exploração com valor agregado desse recurso único" (BEARMAN, 2006, p. 02). Aqui o ponto central é a possibilidade de deixar que uma empresa comercial tenha o controle sobre o futuro da cultura publicada em registro digital. A importância estratégica deste fato já foi percebida por especialistas de vários países quando, na reunião da UNESCO, realizada em São Petersburgo (Rússia) em 2005, endossaram o conceito de "imagem impressa com fonte aberta" como base para todos os programas de digitalização (BEARMAN, p. 4). Tal como a cruzada do software livre, a maturação desse conceito deverá enfrentar muitas batalhas.

5) "o enfoque do Google em relação aos direitos autorais ameaça o nascimento de uma biblioteca digital universal" (BEARMAN, 2006, p. 02).

\subsection{Ações cooperativas}

A biblioteca passou a conviver com o mundo digital nos últimos dez anos, a partir do crescimento da Web, e durante este período houve um incremento da percepção de que a cooperação bibliotecária seria uma ação que não somente reduziria os custos, mas também facilitaria a sobrevivência da biblioteca como instituição social. O campo apresenta-se propício para ações cooperativas mediante convênios. A coleção local não mais será o foco primário de atenção. O compartilhamento de recursos será uma ação crítica, e a comutação bibliográfica passará a ser uma função essencial na nova estrutura da biblioteca convencional.

No contexto digital, as bibliotecas precisam cooperar por três razões: 1) os recursos humanos devem ter o conhecimento tecnológico demandado por inúmeras organizações; 2) o estabelecimento de laços cooperativos aumentará o poder de barganha das bibliotecas em relação aos seus competidores, 3) a adoção de normas e padrões comuns terá impacto nas atividades de reciclagem dos recursos humanos e na adoção de tecnologias que forçarão ações cooperativas - as iniciativas dos arquivos abertos e das teses eletrônicas, por exemplo. 
Aqui vale a pena comentar a importância da Biblioteca Digital de Teses e Dissertações (BDTD, 2007) ${ }^{1}$, projeto coordenado pelo Instituto Brasileiro de Informação em Ciência e Tecnologia (IBICT) e que, em 10 de janeiro de 2008, contava com a participação de 72 instituições de ensino superior (IES), disponibilizando o texto completo de 61604 teses e dissertações defendidas no Brasil. O modelo da BDTD, que completou cinco anos, integra duas iniciativas: a de registro bibliográfico e a de publicação eletrônica de teses e dissertações existentes nos acervos das IES brasileiras. Ao integrar essas duas iniciativas...

[...] o IBICT amplia a abrangência da BDTD e disponibiliza para os usuários um catálogo nacional de teses e dissertações em texto integral e referencial provenientes das IES, possibilitando uma forma única de busca e acesso a estes documentos. O conteúdo das teses disponibilizadas em meio magnético (identificado no portal por um ícone) poderá ser acessado diretamente a partir dos repositórios locais das instituições provedoras de dados. Quanto às teses cujo registro apenas contém as referências bibliográficas, estas poderão ser obtidas por meio de solicitação de cópia, via o Serviço de Comutação Bibliográfica (COMUT), integrado à BDTD" (IBICT, 2007).

As grandes vantagens desta ação cooperativa é que as bibliotecas mantêm a sua autonomia, inserindo em sua base de dados as teses eletrônicas de acordo com a produção da sua instituição e/ou recursos alocados no projeto e, ao mesmo tempo, permitem que seus usuários e os internautas possam consultar e copiar os textos integrais de teses locais ou defendidas em outras instituições brasileiras - e também estrangeiras, pois este projeto está integrado com a rede da National Digital Library of Thesis and Dissertations, que congrega centenas de instituições de vários países. Este tipo de ação cooperativa estimula a criação de novas bibliotecas digitais com custos menores de operação e num menor prazo de implantação.

\section{Considerações finais}

$\mathrm{Na}$ atual dicotomia existente entre biblioteca convencional versus biblioteca digital é interessante discutir os possíveis usos destas duas tecnologias. A biblioteca digital pode ser diferente em relação à biblioteca convencional; cada tecnologia cria os seus próprios serviços e produtos; e pode-se afirmar que a biblioteca digital irá coexistir com outras tecnologias da informação (ADAM, HALEM, NAQVI, 1994). Ela não será uma biblioteca cujo único diferencial seja o seu conteúdo digitalizado. A figura 1 (FIG. 1) mostra a matriz do uso versus conteúdo.

\footnotetext{
${ }^{1}$ Disponível: <http://bdtd.ibict.br/>. Acesso em: 12 mar. 2008.
} 


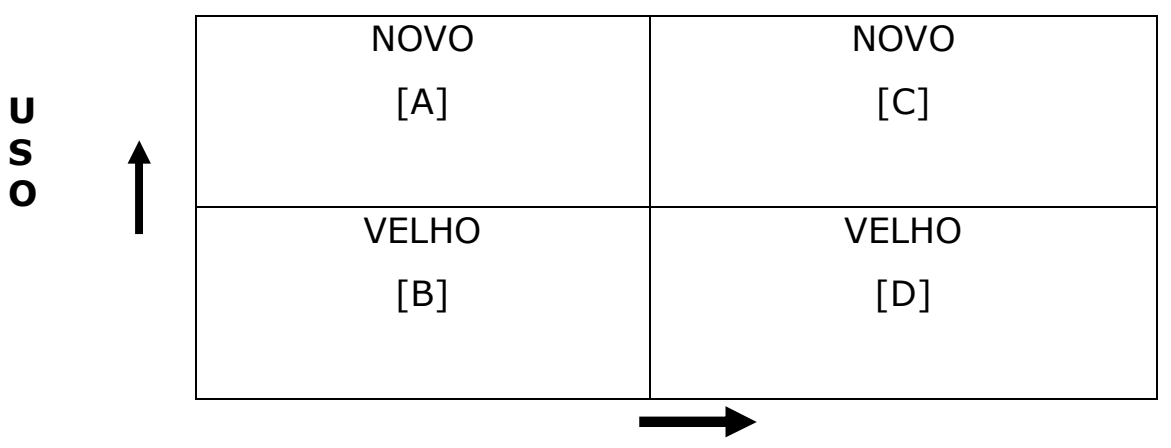

CONTEÚDO

FIGURA 1 - Matriz do uso versus conteúdo.

FONTE - Adaptado de ADAM; HALEM, NAQVI (1994).

Quais serão os novos serviços e produtos oferecidos pela biblioteca digital e quem irá usá-los? Parece que o uso atual da informação está razoavelmente atendido pela biblioteca convencional (FIG. 1, quadrante B). Nos primórdios da implantação da biblioteca digital, quadrante A, é possível que as ações estejam mais voltadas para prover novos usos do conteúdo antigo - e isto é fundamentalmente o oposto da idéia de biblioteca digital - mas, quando o percentual de digitalização dos documentos e a produção da informação totalmente digital alcançar altos níveis, então a biblioteca digital, no quadrante $C$, alcançará a sua maturidade e o reconhecimento público. Até lá, as políticas de conversão de documentos para o suporte digital e a produção de novos conteúdos precisam ser estimuladas, tanto no setor público como no privado.

Mas, como será o relacionamento entre as bibliotecas convencionais e digitais? Há indício de que as bibliotecas continuarão com a custódia dos materiais educativos sólidos, com destaque para os livros. Contudo, elas se tornarão também gerenciadoras de linhas de comunicação com outros locais de conhecimento, com a condição de que as bibliotecas físicas controlem a qualidade das bibliotecas virtuais, decidindo quais conhecimentos existentes em outras instituições merecem menção pelos selecionadores e hiperorganizadores da biblioteca local. (...) O gerenciamento eficaz desses selecionadores de conhecimento será crucial para a qualidade das instituições de ensino no futuro (DERTOUZOS, 1997, p. 241).

Parece que os próximos anos serão um período de mudanças significativas nas bibliotecas, porque elas precisam reagir aos desafios, oportunidades e responsabilidades que se thes apresentam. O elementochave será a sua capacidade de assimilarem os novos paradigmas. No quadro 3 (QUAD. 3) são apresentadas as possíveis mudanças por que estão passando as bibliotecas, comparando-se os contextos atual e futuro - onde coexistem a globalização, a Internet e a biblioteca digital. 
QUADRO 3 - Paradigmas da biblioteca atual e futura

\begin{tabular}{|c|c|}
\hline Contexto atual & Contexto futuro \\
\hline $\begin{array}{l}\text { 1) A maioria dos serviços somente disponíveis } \\
\text { quando ela está "aberta". }\end{array}$ & $\begin{array}{l}\text { Muitos serviços disponíveis } 24 \text { horas, sete dias por } \\
\text { semana }(24 / 7) \text {. }\end{array}$ \\
\hline $\begin{array}{l}\text { 2) Tecnologia limitada para uso por parte do } \\
\text { usuário individual. }\end{array}$ & $\begin{array}{l}\text { Grande expansão da tecnologia a ser utilizada por } \\
\text { usuários individuais. }\end{array}$ \\
\hline $\begin{array}{l}\text { 3) As necessidades de informação e os níveis de } \\
\text { aprendizado e conhecimento são facilmente } \\
\text { identificáveis. A biblioteca pode identificar estes } \\
\text { padrões e planejar produtos/serviços para atender } \\
\text { estas necessidades. }\end{array}$ & $\begin{array}{l}\text { Os usuários apresentam diferentes necessidades e } \\
\text { diversos níveis de aprendizado e conhecimento. } \\
\text { Os padrões são de difícil identificação e mudam } \\
\text { rapidamente. }\end{array}$ \\
\hline $\begin{array}{l}\text { 4) Os usuários gastam tempo com os documentos } \\
\text { impressos e leituras, anotações são feitas a partir } \\
\text { destes documentos, uso de cópias. }\end{array}$ & $\begin{array}{l}\text { Os usuários utilizam bastante os equipamentos } \\
\text { interligados à biblioteca, pouca ou nenhuma } \\
\text { anotação, crescimento maciço de cópias, } \\
\text { downloads e arquivamento digital. }\end{array}$ \\
\hline $\begin{array}{l}\text { 5) Treinamento do usuário oferecido na forma } \\
\text { tradicional, visita orientada, pequenas classes de } \\
\text { treinamento. }\end{array}$ & $\begin{array}{l}\text { Continuação do treinamento tradicional mais o } \\
\text { ensino a distância, tutorial online, treinamento } \\
\text { maciço. }\end{array}$ \\
\hline $\begin{array}{l}\text { 6) Grande apoio do público e do staff às fontes } \\
\text { impressas. }\end{array}$ & $\begin{array}{l}\text { Grande apoio nas fontes eletrônicas e impressas. } \\
\text { Muitos usuários não querem as fontes impressas. }\end{array}$ \\
\hline $\begin{array}{l}\text { 7) Muitas fontes disponíveis impressas; catálogos } \\
\text { e índices disponíveis eletronicamente. }\end{array}$ & $\begin{array}{l}\text { Catálogos e índices disponíveis eletronicamente; a } \\
\text { maioria dos textos completos disponíveis } \\
\text { eletronicamente e crescente a quantidade de } \\
\text { fontes somente no formato eletrônico. }\end{array}$ \\
\hline $\begin{array}{ccccc}\text { 8) Serviço de referência face } & \text { a face } \\
\text { (pessoalmente). }\end{array}$ & $\begin{array}{l}\text { Referência em todos os lugares: pessoalmente, } \\
\text { telefone, e-mail, chat, tempo real, etc. }\end{array}$ \\
\hline $\begin{array}{l}\text { 9) Oferece acesso aos usuários e treinamento } \\
\text { para uso dos documentos que foram adquiridos. }\end{array}$ & $\begin{array}{l}\text { Oferece acesso a recursos } \\
\text { disponíveis livre e gratuitamente. }\end{array}$ \\
\hline $\begin{array}{l}\text { 10) Os usuários têm em mente o "perfil" da } \\
\text { biblioteca e o que pode ser oferecido por ela. }\end{array}$ & $\begin{array}{l}\text { Os usuários podem não saber o que a biblioteca } \\
\text { tem a oferecer => "Tudo não está disponível } \\
\text { gratuito na Internet?" }\end{array}$ \\
\hline
\end{tabular}

Fonte: CUNHA (1999 e 2000).

O contexto que se apresenta é propício para mudar a natureza do empreendimento; no caso da biblioteca convencional, é necessário examinar as enormes possibilidades do futuro e entender que o desafio mais crítico será remover os obstáculos que a impedem de responder às necessidades de uma clientela em mudança, transformar os processos e estruturas administrativas que caducaram e questionar as premissas existentes. Aquela biblioteca que der um passo nesse processo de mudança irá renascer. As que conservarem alguma visão idílica do passado correrão grande risco e terão pouca oportunidade de serem reconhecidas como instituições sociais necessárias.

É vital que o desafio da mudança não seja visto como uma ameaça mortal, mas uma oportunidade para renovação, talvez um renascimento da biblioteca, fazendo com que ela seja de fato um espaço de prazer e aprendizado.

A Internet, notadamente a World Wide Web (WWW ou web), complementa as bibliotecas, porém não irá substituí-las. "As bibliotecas são instituições completamente diferentes da Web. Neste sentido, falar da substituição de uma pela outra parece ser um absurdo" (SHERMAN, 2007, p. 67).

Concluindo, pode-se afirmar que...

[...] sem uma real biblioteca, a digital não será mais do que um punhado de bits. (...) Aqueles que acreditam que uma pilha de bits é suficiente para uma biblioteca robusta nunca 
foram servidos por um bibliotecário - tanto física como virtualmente. (...) As bibliotecas digitais oferecem muitas coisas, mas sem os serviços providos por uma biblioteca de tijolos e cimento e os bibliotecários que fazem com que elas fiquem abertas, elas não serão mais do que uma pilha de bits" (TENNANT, 2007, p. 29).

Juntas, as bibliotecas convencional e digital muito poderão contribuir para o aprimoramento cultural dos nossos cidadãos, estudantes e crianças. Elas, portanto, têm enormes compromissos sociais.

\section{Referências}

ADAM, N. R.; HALEM, M.; NAQVI, S.. Promising research directions in digital libraries. Lectures in Computer Science, n. 916, p. 21-29, 1994.

BEARMAN, D. Jean-Noel Jeanneney's critique of Google: private sector book digitization and digital library policy. D-Lib Magazine, v. 12, n. 12, p. 1-7, Dec. 2006.2 Disponível em: $<$ www.dlib.org/december06/bearman/12bearman.html>. Acesso em: 28 nov. 2007.

BUSH, V. As we may think. Atlantic Monthly, v. 176, n. 1, p. 101-108, July 1945. Disponível em: < www.theatlantic.com/doc/194507/bush>. Acesso em: 13 mar. 2008.

CASTELLI, D. Digital libraries of the future and the role of libraries. Library Hi Tech, v. 24, n. 4, p. 496-503, 2006.

CHOI, Y.; RASMUSSEN, E. What is needed to educate future digital librarians. D-lib magazine, v. 12, n. 9, p. 1-8, Sept. 2006. Disponível em: $<$ www. dlib.org/dlib/september06/choi/09choi.html> Acesso em: 28 out. 2007.

CUNHA, M. B. Desafios na construção de uma biblioteca digital. Ciência da Informação, v. 28, n. 3, p. 257-268, set./dez. 1999. Disponível em: <www.ibict.br/cionline > e <www.scielo.br>. Acesso em: 28 nov. 2007.

Construindo o futuro: a biblioteca universitária brasileira em 2010. Ciência da Informação, v. 29, n. 1, p. 71-89, jan./abr. 2000. Disponível em: <www.ibict.br/cionline $><$ www.scielo.br $>$. Acesso em: 28 nov. 2007.

DEMAS, S. Collection development for the electronic library: a conceptual and organizational model. Library Hi Tech, v. 47, p. 71-80, 1994.

DERTOUZOS, M. O que será: como o novo mundo da informação transformará nossas vidas. São Paulo: Companhia das Letras, 1997. $413 p$.

FONSECA, E. N. Introdução à biblioteconomia. 2. ed. Brasília: Briquet de Lemos Livros, 2007. 152 p. 
INSTITUTO BRASILEIRO DE INFORMAÇÃO EM CIENCIA E TECNOLOGIA - . IBICT. Biblioteca Digital de Teses e Dissertações. 2007. Disponível em: < http://bdtd.ibict.br> Acesso em: 10 jan. 2008.

LOPEZ YEPES, J. Diccionario enciclopédico de ciencias de la documentación. Madrid: Síntesis, 2002. 567 p.

MARCUM, D. B. The future of cataloging. Library Resources \& Technical Services, v. 50, n. 1, p. 5-9, Jan. 2006.

MARKEY, K. The online library catalog, paradise lost and paradise regained? D-Lib Magazine, v. 13, n. 1-2, p. 1-14, Jan./Feb. 2007. Disponível em: <www.dlib.org/dlib/january07/markey/01markey.html> Acesso em: 15 nov. 2007.

SHERMANN, W. 33 reasons why libraries and librarians are still extremely important. Information Outlook, v. 11, n. 6, p. 67-84, June 2007.

TENNANT, Roy. Of real and digital libraries. Library Journal, v. 132, n. 9, p. 29, May 15, 2007. 